\title{
JUEZY PARTE. \\ EL COMPROMISO ESPIRITUAL DEL JUEZ EN EL INTERROGATORIO DE TESTIGOS EN EL JUICIO LABORAL ORAL Y SUS NECESARIOS LÍMITES*
}

\author{
Diego Palomo Vélez ${ }^{* *}$ \\ Pedro Matamala Souper ${ }^{* * *}$
}

\section{SentenCia de La corte de APELACiOnes de ANTOFAGASTA}

Antofagasta, veintiuno de junio del año dos mil once.

Vistos:

Que en esta causa rol único 11440007016-6, rol interno Nº I-6-2011 del Juzgado de Letras del Trabajo de esta ciudad y rol Corte № 97-2011, por sentencia definitiva de tres de mayo de dos mil once, el señalado tribunal hizo lugar a la reclamación de multa deducida por la Empresa Carozzi S.A. dejando sin efecto la resolución dictada por la Inspección Provincial del Trabajo de Antofagasta.

En contra del referido fallo, el señor Abogado de la reclamada, don Manuel Pozo Loo, dedujo recurso de nulidad invocando, en primer lugar, el motivo absoluto de invalidación previsto en el artículo 477 del Código del Trabajo por haberse infringido, sustancialmente, en la tramitación del procedimiento o en la dictación de la sentencia derechos o garantías constitucionales.

En subsidio, alegó la misma causal, pero ahora por haberse dictado la sentencia con infracción de ley que hubiere influido en lo dispositivo del fallo.

También en subsidio invocó el motivo absoluto de nulidad previsto en la letra b) del artículo 478 del Código del Trabajo, es decir, por haber sido pronunciada la sentencia con infracción manifiesta de las normas sobre apreciación de la prueba conforme a las reglas de la sana crítica.

\footnotetext{
* Colaboración recibida el 3 de agosto y aceptada el 20 de septiembre de 2011.

** Abogado; Doctor en Derecho Procesal de la Universidad Complutense de Madrid; Profesor de Derecho Procesal de la U. de Talca. Correo electrónico: dpalomo@utalca.cl.

*** Abogado; Magíster en Derecho del Trabajo y Seguridad Social de la Universidad de Talca. Correo electrónico: pedro.matamala@herreramatamala.cl.
} 
Por último, alegó el motivo de invalidación previsto en la letra c) del citado artículo 478 del Código del Trabajo, esto es, la alteración de la naturaleza jurídica de los hechos sin modificar las conclusiones fácticas del tribunal.

El día 14 de junio del presente año se llevó a efecto la vista del recurso, interviniendo el señor Abogado recurrente.

\section{CONSIDERANDO:}

PRIMERO: Que el recurrente ha deducido recurso de nulidad sustentado, en primer lugar, en la causal del artículo 477 del Código del Trabajo, esto es, por haberse infringido sustancialmente en la tramitación del procedimiento o en la dictación de la sentencia derechos o garantías constitucionales, particularmente aquélla del artículo 19 № 3 de la Constitución Política de la República.

Indica al efecto que la causal se configura por haber desarrollado el Juez de la causa un interrogatorio apartado de la norma que asegura a toda persona el derecho a la garantía aludida.

Señala que la Constitución asegura a todas las personas un justo y racional procedimiento y que el juez interrogó a un testigo en contravención a lo dispuesto en el artículo $454 \mathrm{~N}^{\circ} 6$ del Código del Trabajo, que cita.

Esta norma impone a las partes y al tribunal la prohibición de efectuar preguntas en forma asertiva, contener elementos que determinen la respuesta ni referirse a hechos o circunstancias ajenas al objeto de la prueba.

Añade que si una de las partes sobrepasa los límites legales, la contraria deberá excepcionarse para enmarcar el interrogatorio dentro del marco legal.

Ahora, cuando el tribunal es el que excede el margen legal, resulta lógico que las partes pueden objetar el proceder del tribunal, generando un incidente en el juicio, escuchando a la contraria y resolviendo en el acto, pues de otra forma se abre paso a que el tribunal pueda resolver antojadizamente, sin ningún control, lo que escapa a las normas mencionadas.

Cita parcialmente el interrogatorio practicado por el tribunal a uno de sus testigos, en síntesis, preguntándole si considera injusto o no lo sucedido, si tiene buenos o malos recuerdos de la empresa reclamante y si le gustaría que la empresa ganara o perdiera el juicio; al intentar el señor abogado de la reclamada oponerse a la pregunta, el señor Magistrado le indicó que no tenía ninguna posibilidad de referirse a las preguntas que el tribunal hacía, y que las formulaba para determinar la veracidad de las respuestas, luego de lo cual le ordena al testigo que responda la pregunta.

De este modo, por una parte, el tribunal efectúa preguntas asertivas y con elementos de juicio, respecto de hechos y circunstancias ajenos al objeto de la prueba, en contravención a lo dispuesto en el $\mathrm{N}^{\circ} 6$ del artículo 454 del Código del Trabajo y, al intentar oponerse, ni siquiera dio la posibilidad de argumentar al efecto y menos otorgó traslado, violando el principio de bilateralidad de la 
audiencia, limitándose en señalar que no existe la posibilidad de oponerse al interrogatorio judicial, lo que resulta abiertamente inconstitucional, desconociendo la garantía del artículo $19 \mathrm{~N}^{\circ} 3$ de la Carta Fundamental, también respecto del testigo pues la parte que lo presenta no pudo evitar la práctica de un interrogatorio ilegal.

Añade que el juez trató de formular preguntas para tacha, lo que no es procedente en el proceso laboral conforme a lo dispuesto en el artículo $454 \mathrm{~N}^{\circ} 5$, inciso quinto del Código del Trabajo, que transcribe.

SEGUNDO: Que primeramente debe indicarse que los hechos en los que se basa el recurso son efectivos.

El señor Juez de la causa le informó al señor Abogado de la reclamada que respecto de las preguntas que formulara el tribunal, alguna de las cuales eran de discutible procedencia legal, no tenía ninguna posibilidad de referirse a ellas, en clara alusión que no podía oponerse, objetarlas o incidentar a su respecto, para seguidamente, continuar su interrogatorio al testigo, vedando así a las partes de toda posibilidad de control respecto de las preguntas que formulara.

TERCERO: Que, resulta incontestable que en el procedimiento laboral rige el principio de bilateralidad de la audiencia, pues el mismo está expresamente consagrado en el artículo 425 del Código del Trabajo.

En una primera aproximación puede sostener que este principio no es absoluto desde que, como señala el profesor Cristián Maturana Miquel: "Por la aplicación de este principio no se pretende la intervención compulsiva de las partes, ni es tampoco necesario que ellas sean realmente oídas, sino que exista la posibilidad de igual acceso al ejercicio de sus facultades en el proceso. Por eso se señala que hoy en día se cumple con este requisito brindando a la otra parte la ocasión para ser oída."

Agrega el profesor Maturana: "No puede constituirse un procedimiento en que no exista la posibilidad de darle curso si una de las partes no actúa; lo que se pretende es otorgar a las partes igual posibilidad de ejercicio de sus facultades en el procedimiento, a través de toda la sucesión de actos que lo componen." (Apuntes de clases, Aspectos Generales de la Prueba, pág. 41)

En cuanto a su contenido, siguiendo al profesor Eduardo Couture, sus aplicaciones más importantes son las siguientes:

“a) la demanda debe ser necesariamente comunicada al demandado; b) la comunicación debe hacerse con las formas requeridas en la ley bajo pena de nulidad; todo quebrantamiento en las formas de emplazamiento entraña el riesgo de que el demandado no haya sino efectivamente enterado de la demanda; c) comunicada la demanda se otorga al demandado un plazo razonable para comparecer y defenderse; la doctrina denomina esta circunstancia, la garantía de "su día ante el tribunal", d) las pruebas deben ser comunicadas al adversario para que tenga conocimiento de ellas antes de su producción; e) toda prueba 
puede ser fiscalizada por el adversario durante su producción e impugnada después de su producción; f) toda petición incidental que se formule, ya sea durante el debate, ya sea durante la prueba, debe sustanciarse con audiencia del adversario, salvo disposición en contrario; g) ambas partes tienen iguales posibilidades de presentar sus exposiciones de conclusión o alegatos y de impugnar mediante recursos las resoluciones que les sean adversas;" (Fundamentos del Derecho Procesal Civil, págs. 183 y 184)

En el ámbito del proceso penal, pero plenamente aplicable a la especie, se ha dicho que este principio importa, de acuerdo al profesor Alberto Bovino (EI Nuevo Código Procesal Penal de la Nación, -referido a Argentina- varios autores, pág. 184) que las partes tengan: "a) La posibilidad de ser oídas por el tribunal; b) la posibilidad de ingresar pruebas; c) la posibilidad de controlar la actividad judicial y de la parte contraria; d) la posibilidad de refutar los argumentos que puedan perjudicarlas."

Agrega este profesor que una consecuencia de este principio es: "el deber que incumbe al juzgador respecto del fundamento de su sentencia: es indispensable que su convicción emane de los actos del debate, ya que son éstos los que han podido ser apreciados y discutidos por las partes y han estado a su alcance."

Por último, debe indicarse que este principio tiene reconocimiento constitucional, precisamente, en la garantía señalada por el recurrente. Así, se ha sostenido a propósito de la garantía del artículo $19 \mathrm{~N}^{\circ} 3$ inciso quinto de la Constitución Política de la República: "El debido proceso legal, o sea el 'due process of law', fue desarrollado por el profesor de la Facultad de Derecho de la Universidad de Chile, don José Bernales Pereira en las sesiones 100 y 103 de 9 y 16 de enero de 1.975 ante la Comisión de Estudios sobre nuestra Constitución. En dicha exposición se precisó que el establecimiento de este precepto significaba consagrar en la Constitución los principios formativos del proceso y del procedimiento, que son también de derecho básico, de derecho natural, que serían la imparcialidad del tribunal, la jurisdicción, competencia. En seguida el principio que don Rafael Fernández Concha, en su tratado de derecho natural, llama de disertación, o sea, la posibilidad que una persona pueda oponerse a la pretensión contraria; al principio de contradicción, el principio de bilateralidad de la audiencia." Citado por don Cristián Maturana Miquel, opus cit. pág., 43)

CUARTO: Que así, la vigencia del principio de bilateralidad de la audiencia impone al juez la obligación de permitir, en los distintos actos del procedimiento, que las partes efectúen las alegaciones que estimen pertinentes, dentro, claro está, de respeto del normal desenvolvimiento del proceso y de las facultades de conducción del tribunal y ello también alcanza, como se vio, a la rendición de la prueba, desde que, en todo caso, tienen la posibilidad de intervenir en la producción de la misma, lo que también supone, el control de la forma en 
que se produce pues, sin perjuicio de las facultades oficiosas del tribunal, la vigencia del principio impone la existencia de un modelo de juicio adversarial que supone un conjunto de controles horizontales entre las partes y, también, respecto de la actividad del tribunal.

QUINTO: Que el principio del contradictorio o bilateralidad de la audiencia, asume un carácter de garantía en lo que dice relación con el derecho de defensa, incluido en el concepto de debido proceso.

Así, como se adelantó, una de las manifestaciones de este derecho, supone que las partes estén en condiciones de controlar y controvertir la prueba, lo que, tratándose de prueba testimonial supone, indefectiblemente, conforme a lo dispuesto en el articulo $454 \mathrm{~N}^{\circ} 6$, la posibilidad de impedir que se interrogue a los testigos utilizando métodos vedados, como la formulación de preguntas asertivas, ni aquellas que contengan elementos de juicio que determinen la respuesta ni relativas a hechos o circunstancias ajenas al juicio.

Esta garantía de control probatorio, evidentemente se relaciona con la calidad de la prueba que ingresa al juicio y sobre la cual el juez del juicio debe formar su convicción, y supone que no toda prueba es válida para tal fin, sino, exclusivamente, aquellas que se rinden con plenas condiciones de legitimidad, igualdad de oportunidades, y evitando toda injerencia indebida, para que de esta manera dicha información resulte confiable para la adecuada resolución del asunto. Es por ello, por ejemplo, que se impide formular preguntas que sugieran la respuesta, pues podría suponerse en el declarante una predisposición a contestar positivamente las afirmaciones que realice, particularmente el abogado que lo presenta al juicio y con el cual suele tener una vinculación previa al mismo, lo que se traduce, en síntesis, que los datos que entregue no serían plenamente fiables para la decisión de la controversia.

Manifestación de este derecho de controlar la prueba que las partes incorporan al juicio, especialmente la calidad de la información que la misma contiene, resulta pues, el mecanismo de objeciones de preguntas que se deriva del artículo mencionado.

SEXTO: Que de acuerdo a lo dicho, resultando el juicio una controversia entre partes, regida, entre otros, por el principio de bilateralidad de la audiencia o contradictorio, con plena vigencia del derecho a controlar la prueba que ingresa al mismo para asegurar la confiabilidad de la misma, surge la necesidad de analizar la posibilidad que el tribunal, en virtud de la vigencia del principio de impulso procesal de oficio, quede al margen del control de los intervinientes respecto de las preguntas que formule, como resulta ser la pretensión del señor juez en el juicio al oponerse de plano a cualquier tipo de objeción respecto de las preguntas que enuncia.

Convengamos que el impulso procesal de oficio busca, por una parte, asegurar el principio de celeridad también consagrado en la legislación laboral, 
impidiendo la actividad dilatoria de las partes y en todo caso, el retraso o demora injustificada en la resolución de estos conflictos atendida la naturaleza alimenticia y asistencial de muchos de los derechos que están en juego.

Por otro lado, sobre la base de la desigualdad de las partes en el proceso, la búsqueda de la verdad real se erige en un objeto de proceso, y por ello se le entregan al juez facultades probatorias oficiosas, tanto en la proposición como en la producción de la prueba, como aparece de lo dispuesto en los artículos $453 \mathrm{~N}^{\circ} 9$ y $454 \mathrm{~N}^{\circ} 6$ del Código del Trabajo.

Resulta necesario indicar, no obstante su evidencia, que ciertamente el tribunal, en la práctica, puede vulnerar las formas legítimas de interrogación señaladas en la ley, pues podría interrogar sobre hechos que no son materia de la controversia, efectuar preguntas asertivas y, todavía más, contener elementos de juicio que condicionen la respuesta.

Conclusión pacífica debiera ser que ello no resulta procedente pues, por una parte, la norma no distingue respecto de quienes rige la prohibición y por tanto, debe extenderse al interrogatorio del tribunal, como por otro, si se analiza la ratio de la prohibición, como se adelantó, controlar la calidad de la información que ingresa al juicio, deviene que ésta aún más debe regir para el tribunal, en la medida que puede afirmarse que, especialmente ciertos testigos de bajo nivel intelectual o escaso nivel cultural, pudieran ser proclives a responder positivamente las afirmaciones que efectúa un juez.

Consecuente con ello, debe también aceptarse que las partes tienen la potestad de oponerse al ejercicio abusivo o ilegal de las facultades oficiosas del tribunal, particularmente al momento de la producción de la prueba.

La facultad de las partes, que asume dimensión de garantía, de controlar la prueba que ingresa al juicio, es un pilar del modelo de juicio laboral y en general, del debido proceso. Luego, la mera posibilidad que cierta prueba que, según el caso, pueda ser decisiva para la demostración de hechos del juicio quede al margen del señalado control, constituye un grave o sustancial quebrantamiento a las bases del modelo y resulta inaceptable.

Por lo demás, si cada una de las resoluciones que dicta el tribunal, salvedad de la sentencia definitiva, para la cual se dispone del recurso de nulidad, o aquellas interlocutorias que ponen término al juicio o hacen imposible su continuación, pueden ser objeto de recurso de reposición, -artículo 475 del Código Trabajo: clara manifestación del principio de bilateralidad de la audiencia-con mayor razón la formulación de una pregunta, fuera de los estrictos marcos establecidos en la ley, puede y debe ser materia de impugnación directa por la parte que se sienta afectada, désele a la misma el nombre técnico de objeción, empleado en litigación de juicio oral, incidente, o cualquier otro.

La posibilidad de impugnación respecto de actuaciones del tribunal, por lo demás, es base de todo nuestro sistema procesal y regla general cuando se 
hace por vía de retractación, salvedad de resoluciones que tengan el carácter de sentencias definitivas, lo que no puede predicarse de las preguntas que el tribunal pueda formular en el curso de la declaración de un testigo.

SÉPTIMO: Que, corolario de lo anterior, la circunstancia que el tribunal haya anunciado que, de plano, las preguntas que formulara no podían ser objetadas por los intervinientes, ha impedido a las partes el ejercicio de una facultad inherente a la idea de debido proceso pues, en términos amplios, se vio privado de la posibilidad de controlar la prueba que ingresaba al juicio.

Por lo mismo, corresponde acoger el recurso de nulidad intentado por la defensa.

OCTAVO: Que debiendo acogerse la primera de las causales de nulidad invocadas por el recurrente, se hace innecesario el análisis de aquellas invocadas en carácter subsidiario.

Por estas consideraciones y visto lo dispuesto en los artículos 474, 477, 479 y 482 del Código del Trabajo, SE ACOGE el recurso de nulidad deducido por don Manuel Pozo Loo por la reclamada Inspección Provincial del Trabajo de Antofagasta, en contra de la sentencia definitiva de tres de mayo del año dos mil once, pronunciada por el Juzgado del Trabajo de Antofagasta doña Sol López Pérez y, en consecuencia, SE ANULA la sentencia recurrida y el juicio en que la misma se dictó debiendo el juez no inhabilitado que corresponda disponer la realización de un nuevo juicio oral.

Regístrese, comuníquese y devuélvase.

Rol Corte No 97-2011.

Redactada por el Ministro Dinko Franulic Cetinic.

No firma la Ministra Sra. Cristina Araya Pastene, no obstante haber concurrido a la vista y al acuerdo de la causa por encontrarse en comisión de servicio.

Pronunciada por la Primera Sala integrada por los Ministros Sr. Dinko Franulic Cetinic, Sra. Cristina Araya Pastene y el Abogado Integrante Sr. Fernando Orellana Torres. Autoriza la Secretaria Titular Sra. Claudia Campusano Reinike.

II. FIN DEL PROCESO Y PAPEL DEL JUEZ LABORAL en MATERIA PROBATORIA. LímiteS

La sentencia transcrita pone encima de la mesa de discusión uno de los temas esenciales de actual debate en el foro, y que dice relación con los límites de actuación del tribunal en materia de prueba' ${ }^{1}$.

La pregunta que nos recuerda este fallo es hasta dónde llega la potestad de actuar de oficio, y qué herramientas o mecanismos de control tienen las partes a su disposición, para controlar la calidad de la información que se ingresa en

1 En la actualidad constituye un tema permanente entre los abogados litigantes, la discusión sobre el rol del juez y, principalmente, cómo este rol se ha ido hipertrofiando, afectando la noción de proceso, los derechos de las partes y también el papel mismo del juzgador. 
el proceso laboral, particularmente desde el punto de vista del control de los testigos, así como también, de qué forma podemos evitar la adquisición del proceso por parte del juez.

En la dirección de abordar este tema lo primero que debemos anotar es que compartimos que la tutela y realización del Derecho objetivo es el contenido fundamental de la función jurisdiccional, pero ello no debe hacernos olvidar que en la gran mayoría de los casos de la jurisdicción lo hace justamente a propósito de existir una contienda entre partes. Esto es, la jurisdicción persigue tutelar y realizar el Derecho establecido, pero tiende a resolver controversias o contiendas con el fin de lograr la paz social.

Junto a lo anterior, debe tenerse claridad en lo siguiente, muy especialmente cuando se trata de la aplicación de las normas laborales: no es posible decir el Derecho sobre casos concretos de forma instantánea (por más que se postule la instrumentalidad y efectividad del proceso y el predominio de la justicia en las decisiones ${ }^{2}$ ), sin que previamente ocurra la verificación de una serie de actos que preparan y sostienen el resultado de la función jurisdiccional.

Esa serie de actos dan forma a no otra cosa que lo que conocemos como proceso, que debe estructurarse sobre la base de dos posiciones distintas y enfrentadas, y de un juez que, situado neutralmente por encima de ellas, presencia y dirige una controversia entre quienes ocupen esas posiciones ${ }^{3}$. Esta cuestión debe llevarnos a señalar, como corolario, que los derechos de las partes en el proceso importan no solamente el deber de los órganos jurisdiccionales de realizar el proceso, sino que además de realizarlo conforme a los principios que informan la intervención de las partes, cuales son básicamente el de contradicción, de igualdad y de imparcialidad. Se ha sentenciado: o bien el proceso se ajusta a estos principios, o los abandona y, en ese evento, pasa a convertirse en una pura ficción o un simulacro de proceso ${ }^{4}$.

Tales principios son fundamentales de cara a la noción de proceso, pero también lo son, y muy especialmente, de cara a la principal actividad del proceso, la prueba, que debe hacer efectivos estos postulados elementales de justicia. En este ámbito, el de la prueba, es de suyo importante atender a la calidad de la información que se introduce al juicio para acreditar las afirmaciones de las

\footnotetext{
2 Véase: Dinamarco, C. La instrumentalidad del proceso, Traducción de Monroy P., José, Ed. Communitas, Lima, 2009.

3 Véase en esta línea de pensamiento: De la Oliva Santos, A.; Diez-Picazo Giménez, I.; Vegas Torres, J., Derecho Procesal: Introducción, 3ª Edición, Ed. Ramón Areces, Madrid, 2004.

${ }^{4}$ Véase especialmente dos obras de Alvarado Velloso: Alvarado Velloso, A. Garantismo procesal contra actuación judicial de oficio, Ed. Tirant lo Blanch, Valencia, 2005; Alvarado Velloso, A. La prueba judicial: reflexiones sobre la confirmación procesal, Ed. Librotecnia, Santiago, 2009. Y de reciente publicación en nuestro país: Alvarado Velloso, A. Lecciones de Derecho Procesal Civil, Ed. Thomson Reuters, Santiago, 2011.
} 
partes. Ya más concretamente, debe haber normas que permitan a las partes y al juez, depurar la información que se ingresa al proceso, y una vez inserta en el mismo, poder también someter las mismas a distintos ejercicios de control que vayan depurando la información en forma eficiente.

Como señalaremos más adelante, las herramientas de depuración de la información en nuestro sistema procesal laboral, son bastante exiguas, por cuanto si bien existen algunas normas que se refieren a este tema, no existen mecanismos entregados directamente a las partes para controlar la actuación del juez en este proceso de depuración de la calidad de la información. De hecho, en el Código del Trabajo, las normas sobre control del rol del juez son prácticamente inexistentes, porque el legislador quiso entregarle al juzgador profesional, y supuestamente competente, un rol sin contrapesos, lo que a nuestro juicio, sin lugar a dudas, afecta una noción de proceso que sea verdaderamente respetuosa de los postulados elementales antes enunciados, y que dan cuenta de un debido proceso real.

Por ejemplo, y a propósito de la sentencia en comento, si bien existen actualmente en el proceso laboral oral herramientas para poder objetar las preguntas que se formulen a los testigos, y aún cuando no existe un Código de evidencia que nos determine de manera precisa la procedencia, no existen instrumentos efectivos explícitos para controlar ese interrogatorio cuando se hace por el juez. Es por esta razón que la sentencia que traemos a colación adquiere una relevancia especial al establecer que las preguntas que realiza el juez sí se encuentran sometidas al control por las partes.

Con la reforma procesal laboral el rol del juzgador pasó de ser pasivo, y prácticamente invisible en el contexto de un modelo escriturado y con una dinámica de delegación de funciones, al establecimiento de un magistrado profesional y especialista, dotándolo de una serie de potestades públicas explícitos, especialmente en materia probatoria, que lo han transformado en la manifestación de lo que no pocos llaman juez autoritario, el cual actúa en el proceso oral de conformidad a su particular criterio, incluso manteniendo su propia teoría del caso, con independencia de la de las partes, sin que se prevean normas claras relativas al necesario control de esta actuación, indispensable para que la garantía del debido proceso sea una realidad.

Y esto es de suyo importante, porque la oralidad en sí misma, carece de sustancia si no se acompaña de una serie de consideraciones relevantes, y que dicen relación con las decisiones políticas que se deben adoptar, porque no se trata solamente de un cambio en el discurso, sino que la decisión sobre el rol de las partes, y del juez especialmente, así como la forma en que se incorporarán las pruebas y en general, sobre cómo se plasma el debido proceso en esto, resultan de tanta trascendencia que por simple se suele olvidar. 
Porque la cuestión es simple, por mucho que a propósito de la reforma procesal laboral se hayan olvidado unos postulados que, como se adelantó, son básicos y elementales. El juez no debería tener intervención en la producción o rendición de pruebas, en el juicio oral, porque deviene en lo que la mejor doctrina ha llamado el compromiso espiritual del juez, ${ }^{5}$ esto es, la pérdida de la imparcialidad subjetiva y objetiva, lo que afecta sin lugar a dudas en la decisión final, dado que el juzgador se compromete en el proceso más allá del interés objetivo en el caso, y pasa a ser una parte más.

Pues bien, entusiasmado nuestro legislador con la doctrina procesal que desde hace tiempo viene predicando un fuerte aumento de los poderes de los jueces a propósito del tránsito desde un sistema escrito a uno oral, concretó la configuración de un juez con muy amplias potestades. Según alguna doctrina, este papel judicial activo sólo podría ser asegurado en el contexto de un proceso oral, de allí la vinculación entre la fórmula de la oralidad y la asignación de considerablemente mayores potestades a los jueces, en especial en los denominados "procesos sociales", donde se señala estarían autorizadas y serían necesarias potestades inquisitivas, justificadas sobre todo por la necesidad, "simbólica" o "real", de asistencia a la que se considera la parte más débil del proceso que, desde el Derecho Laboral, están contestes en denominar desigualdad compensatoria de las diferencias sociales, culturales y económicas y la conciben al servicio del descubrimiento de la verdad material en el proceso ${ }^{6}$. Se plantea, a mayor abundamiento, que se debe tomar conciencia que los jueces ya no son sólo la boca de la ley, sino también tienen responsabilidades sociales lo que justificaría su activismo ${ }^{7}$. No podemos estar de acuerdo con esto, cuando ese activismo se transforma en no pocas veces en un activismo ideológico ${ }^{8}$ relevante dentro

\footnotetext{
5 Véase especialmente: Alvarado Velloso, Adolfo, "La Prueba Judicial. Reflexiones críticas sobre la confirmación judicial", Santiago, Librotecnia, 2009. El autor hace un excelente relato sobre cómo el juez interventor adquiere un carácter que involucra necesariamente su compromiso no sólo intelectual sino espiritual con el proceso, lo que termina afectando su imparcialidad.

6 Barbosa Moreira, J., "La significación social de las reformas procesales", Revista de processo 131, 2006; Pellegrini Grinover, A., "Modernitá del diritto processuale brasiliano", en VV.AA., Scritti in onore di Elio Fazzalari, Vol. II, Ed. Giuffré, Milano, 1993; ChIARlon,, S., "Reflexiones microcomparativas sobre ideologías procesales y comprobación de la verdad", Revista Internauta de Práctica Jurídica №24, 2009; VesCovI, E., "Los poderes probatorios del juez civil en los nuevos sistemas procesales", en, Studi in onore di Vittorio Denti, Vol. II, Ed. Cedam, Padova, 1994.

7 Véase: Peyrano, J., "El perfil deseable del juez civil del siglo XXI", en Silva, J.; García, J.; Leturia, F. (Coords.), Justicia civil y comercial: una reforma pendiente. Bases para el diseño de la reforma procesal civil. P. Universidad Católica de Chile, Universidad Autónoma de Madrid, Instituto Libertad y Desarrollo, Santiago, 2006.

${ }^{8}$ Entendemos ideológico desde las ideas, no sólo con un tinte de carácter meramente político, sino que desde el punto de vista filosófico y sociológico que tiene que ver con las visiones fundamentales de la sociedad, el rol del proceso y de las partes y el juez.
} 
del proceso que finalmente priva a las partes de la necesaria imparcialidad, y menos cuando no tienen las partes las herramientas de control necesarias, para depurar la información y dejar dentro del proceso la información de mayor y mejor calidad posible.

El juez en el proceso laboral oral chileno tiene un rol activo en exceso, mostrando en la realidad ese reforzamiento de poderes, incluso sustituyendo a las partes, como ha sido el caso de la sentencia que se cita. Frente a esto es que sostenemos que la configuración de un juez activo por parte del legislador no puede significar el reconocimiento de un juez cuyas potestades no tengan límites. La reciente reforma procesal laboral le ha conferido amplios poderes de dirección formal y material (donde destacan los poderes en materia de prueba). Con todo, es necesario que se entienda por todos los operadores del nuevo sistema procesal laboral que ninguno de los poderes conferidos a los jueces es absoluto, sino que están sujetos a límites. Este debe ser el punto de partida a la hora de analizar el problema que genera el renovado papel activo de los jueces y proponer una re-lectura de estas potestades que, estableciendo cuales son los límites, sea efectivamente compatible con derechos y postulados procesales fundamentales, impidiendo desbordes.

Un sector de la doctrina procesal que se ha ocupado del tema de las potestades judiciales ha señalado que al establecer compatibilidad de funciones procesales, entre el juzgar y probar, se está afectando la imparcialidad del juez, porque se le exige al juez desplegar una actividad para la cual finalmente no se encuentra llamado. Es olvidarse incluso del desinterés objetivo de la Jurisdicción, por cuanto se le exige al juzgador algo más que ser juez, lo que entendemos afecta la sustancia de la administración de justicia ${ }^{9}$, si no se contemplan los límites adecuados.

Si a esto le sumamos la cuestión de la calidad de la información que podemos agregar al proceso y las vagas normas sobre su adecuada depuración, y las casi nulas herramientas de control, entonces estamos frente a un problema, que desde el punto de vista del debido proceso, es mayúsculo.

\section{LA CUESTIÓN DE LA CALIDAD DE LA INFORMACIÓN QUE SE INSERTA AL PROCESO: GARANTÍAS PROCESALES Y CELERIDAD}

El juicio oral laboral nacional, adolece de un diseño que permita tener certeza respecto a que existirá una limpieza razonable de la información que permita incorporar prueba de calidad y fiable al proceso $^{10}$, y esto es simplemente

${ }_{9}^{9}$ MONTERo Aroca, Juan, Sobre la Imparcialidad del Juez y la Incompatibilidad de funciones procesales, Ed. Tirant lo Blanch, Valencia, 1999. El autor hace un análisis desde el punto de vista penal que, en su parte sustancial, resulta aplicable a la materia laboral que estamos analizando.

${ }^{10}$ Esto se refiere al descubrimiento y a la refutación, ambos elementos indispensables. 
porque el debido proceso no ha sido considerado como el elemento orientador al momento de legislar.

Esto es vital: un elemento central de todo proceso, en especial de los procesos orales, es el respeto a los postulados mínimos del debido proceso. En eso no puede ni debe existir discusión de ninguna especie, pese a que en la reforma este derecho no ha sido estimado ni tenido en consideración como el elemento primordial en la arquitectura del sistema ${ }^{11}$.

En el nuevo juicio del trabajo, al igual que en los demás procesos, nuestro legislador debió haber tenido en cuenta la forma en que se inserta información fiable al juicio, y cómo se efectúa el correcto control de calidad de la misma, fundamentalmente porque los poderes exorbitantes del juez pueden dar pábulo a abusos e incluso a pruebas ajenas a las teorías de las partes, o peor aún, a sentencias que se sustentan en la teoría del juez, que no conoce los hechos en forma completa ni profunda ${ }^{12}$.

Bien se ha dicho que las partes son las que mejor conocen los hechos, y deben ser ellas las Ilamadas a producir libremente prueba para que el juez forme su convicción, pero claramente en un sistema como el del proceso laboral chileno, ello se difumina cada vez más desde que tenemos un juez con esta posición dominante, y que siente que tiene que sustituir al litigante negligente o peor aún que es él quien mejor puede llegar a la verdad, lo que por cierto no solamente no es cierto, sino que distorsiona el proceso, mostrándose el juez en la práctica como una parte más, pero con poderes distintos de las demás. Este compromiso espiritual del juez con el proceso y las partes, así como la interpretación desproporcionada de sus potestades públicas de oficio, hacen que en la práctica ocurran cosas como las que describe la sentencia objeto de este artículo, porque el juez entiende que él es el Ilamado a asegurar la obtención de un resultado justo, y las partes, entonces, pierden toda relevancia. En efecto, lo que señalan los considerandos Segundo y Séptimo de esta sentencia, en el sentido que el juez había anunciado que sus preguntas no eran objetables, resulta ser absolutamente inaceptable, desde el punto de vista precisamente del control de la calidad de la información, y del debido proceso.

\footnotetext{
${ }^{11}$ Llama bastante la atención que la discusión parlamentaria se haya centrado en la constitucionalidad del procedimiento monitorio y no en cosas realmente relevantes para el proceso en sí mismo, como es la calidad de la información que se incorpora al juicio y los poderes del juez.

12 Véase Ltuch, Xabier Abel, Sobre la prueba y el derecho a la prueba en el proceso civil. En: http:// vlex.com/vid/prueba-derecho-proceso-civil-444445 [visitado el 29/04/2011], que desarrolla un muy buen análisis sobre la importancia que posee constitucionalizar el derecho a la prueba y sus efectos positivos en la forma en que las partes se plantean finalmente en el juicio oral, de tal modo que los poderes oficiosos del juez quedan también disminuidos aunque existan, porque se entiende, que las partes actúan distinto frente a una garantía que ante una mera carga procesal.
} 
Con todo, no obstante tratarse de algo absolutamente inaceptable lo que el juez de este juicio ha hecho, es justamente lo que habitualmente acontece: el juez del trabajo puede preguntar a los testigos libremente, sin embargo no se permite a las partes que objeten dichas preguntas, imponiéndose hasta ahora la tesis de que las preguntas de los jueces no son objetables (sólo lo serían las preguntas formuladas por las partes litigantes y ellos no lo son). Los poderes que les reconoce la ley les permitiría hacer lo que les parezca más conveniente, lo que desde la perspectiva de una correcta comprensión de la noción del debido proceso y del derecho a la prueba está errado, porque la prueba que incorpora o repele el juzgador, sea a través de las partes o de propia iniciativa, así como la forma en que se efectúe la señalada incorporación y las posibilidades de las partes de impugnar, refutar y replicar, resulta esencial para lograr una prueba fiable. En un sistema como el nuestro, he aquí el problema, eso no se produce necesariamente: si las partes no pueden objetar, refutar y replicar al juez de la causa, resulta evidente que se puedan producir distorsiones relevantes.

Es justamente este problema del modelo lo que la sentencia de la Corte de Apelaciones de Antofagasta resuelve de muy buena manera, porque señala que cuando es el Tribunal el que ha excedido el margen legal de las preguntas, resulta lógico que las partes puedan objetar el proceder del Tribunal, generando un incidente, porque de otra forma, sigue la sentencia, se abriría paso a que el Tribunal pudiera resolver antojadizamente, sin ningún tipo de control. Este razonamiento, plasmado en la sentencia de alzada, aparte de lógico, legal y razonable, no hace sino aplicar el debido proceso en el caso concreto.

Entonces, la pregunta que cabe formularse radica en qué necesitamos, o mejor dicho, qué necesita el proceso para que la prueba que se incorpora o inserta resulte fiable, y si dicha fiabilidad es necesaria para los fines del proceso. Sobre lo primero, entendemos que se requiere la consagración del debido proceso según estándares internacionales ${ }^{13}$, libertad probatoria en cuanto a su ofrecimiento, incorporación y refutación, un estándar de litigantes alto que permita contrapesar al juez autoritario, y en especial, entender que el juzgador puede ser rebatido en sus preguntas o actuaciones, no sólo a través de los recursos normales u ordinarios, sino también, por medio de las objeciones que pueden hacerse a sus preguntas. Es el mínimo control que, desde el debido proceso, es exigible.

Sobre el necesario control del juez interventor, comprometido en la prueba más allá de lo razonable, es claro que la fiabilidad es indispensable, ya que es la única forma en que el Estado se protege de abusos, y es la única forma en que las partes pueden defenderse frente a ellos.

${ }^{13}$ Entendemos esto como lo entiende la Convención Americana de Derechos Humanos. 
¿Cómo se traduce esta fiabilidad en los hechos? En mecanismos que mejoren la calidad de la información que se ofrece e incorpora en el juicio, en la limitación del rol del juez y en especial en la libertad de refutar y replicar todas las pruebas que se incorporan, incluyendo las del Tribunal.

A estas alturas y con la normativa procesal laboral vigente no se trata tanto de oponerse absolutamente a la existencia de estas potestades oficiosas, conformándose con plantear el tema como una elección entre dos alternativas que se muestran como incompatibles: una tutela judicial eficaz o el garantismo procesal ${ }^{14}$. Se compartan más o se compartan menos las reforzadas potestades judiciales, éstas tienen existencia y se están haciendo notar en el marco del nuevo proceso, lo que impone que los esfuerzos vayan más en la línea de, sin renunciar a las legítimas visiones, superar la mera defensa ellas en la lógica del antagonismo puramente dogmático ${ }^{15}$, planteando una re-interpretación respetuosa de los postulados que son propios de todo proceso, inclusive el laboral, de modo que estos poderes del juez, tengan su debido correlato de control por las partes, mejorando así la calidad de la información y finalmente mejorando sustantivamente la calidad de proceso al que accedemos ${ }^{16}$.

Dicho de otro modo, a estas alturas no se trata tanto de si esto puede suceder o no (nos referimos a los mayores poderes conferidos a los jueces del trabajo, especialmente en lo que dice relación con la actividad probatoria), sino "cómo" debe suceder, para así evitar los abusos judiciales que se puedan traducir en decisiones que causen perjuicios a una de las partes y ventajas indebidas a la otra ${ }^{17}$.

Así, las normas que regulan el juicio oral deben establecer la forma en que las partes pueden ofrecer e incorporar al juicio las pruebas, facilitando el conocimiento de la otra parte de las pruebas con anticipación para que pueda preparar su defensa. Pero también se debe establecer libertad en la objeción y refutación de las pruebas que se pretende incorporar al juicio, de modo que las partes puedan demostrarle al juez que las pruebas que se acompañan son eficientes o no para acreditar los hechos que se discuten. Este derecho de las partes debe alcanzar necesariamente al juez, por cuanto de otro modo, el sen-

\footnotetext{
${ }^{14}$ En la doctrina laboral criolla véase: PALAVECINO CÁCERES, C., "El retorno del inquisidor. Las potestades judiciales en materia probatoria en el procedimiento laboral chileno", Revista Laboral Chilena $\mathrm{N}^{\circ} 173$.

15 Véase especialmente: PICó I Junor, J., "El Derecho procesal entre el garantismo y la eficacia: un debate mal planteado", Revista Iberoamericana de Derecho Procesal №4.

${ }^{16}$ Otro tema relevante, que no trataremos acá, es el resabio del sistema anterior en torno a la libertad de réplica en las preguntas de las partes y del juez. Nuestros jueces entienden que las partes sólo tienen posibilidad de replicar luego del contraexamen de la parte o de las propias preguntas del interrogatorio del juez, desconociendo el tenor literal de la norma recogida en el Código del Trabajo y estableciendo restricciones en torno a la refutación y réplica no existentes, y que finalmente también afectan a la calidad de la información.

17 Especialmente interesante resulta la lectura de: TAruffo, M., Páginas sobre justicia civil, Ed. Marcial Pons, Madrid, 2009.
} 
tenciador puede apropiarse del proceso a su antojo, sin control alguno, y eso no sólo no es deseable, sino que tampoco es aceptable.

Como si la asignación de amplísimos poderes no bastase para complicar el escenario de cara al debido proceso, debe anotarse también que el sistema recursivo que se recoge por el legislador para el proceso laboral oral es muy limitado (por una desbordada asunción de la regla procesal de la inmediación judicial), lo que se alza en otra razón por la cual es necesario que existan disposiciones suficientes que permitan contar con unas pruebas de calidad y fiables, con información relevante y debidamente contrastada, entregándose (contra) poderes a los litigantes a fin que puedan enfrentar los amplios poderes del juez.

Esto es indispensable, y no puede ni debe ser transado por las partes, que deben a través de estas herramientas, ayudar al juez a tomar la mejor decisión con la mayor cantidad de información disponible, pero siempre que ésta sea a su vez la de mejor calidad posible.

Algunos afirman que estos mecanismos de control entorpecen la celeridad del proceso, la rápida solución del asunto y que finalmente afecta a la parte más débil, el trabajador, con ese argumento tan extraño de que "en materia laboral las cosas son distintas". Desde ya, podemos indicar que la rapidez o celeridad en un proceso laboral que pasó de tardar aproximadamente 36 meses a uno que se demora en promedio tres, la verdad, no se ve demasiado afectada porque existan herramientas de control. Pero más allá de la mera estadística de la duración de los procesos, estos elementos que las partes deben tener a su disposición permitirían una mejor decisión (por ser de mayor calidad), lo que debe recordarnos que el objetivo de transitar desde un modelo de proceso escriturado a uno oral (predominantemente oral, en rigor) no viene sólo dado por la búsqueda de mejorar los tiempos de la Justicia (como pudiera creerse), sino también en mejorar la calidad de la respuesta jurisdiccional ${ }^{18}$.

\section{Posibilidad de objetar preguntas del interrogatorio judicial. Restricciones LEGALES INEXISTENTES AL ACTUAR JUDICIAL OFICIOSO. MECANISMOS DE CONTROL DE LAS PARTES VERSUS EL MONOPOLIO DE LA JURISDICCIÓN}

Lamentablemente en este punto, estamos en el absoluto despoblado, por cuanto si bien la ley es bastante amplia, las normas procesales que el Código del Trabajo nos entrega son exiguas en lo que se refiere precisamente al control que las partes pueden ejercer. En nuestra Constitución tampoco hay mucho. Si consideramos las Actas Constitucionales, donde se encuentra su "historia fide-

${ }^{18}$ Véase: TARUfFo, M., "Oralidad y escritura como factores de eficiencia en el proceso civil", en CARPI, F.; Ortells, M., Oralidad y escritura en un proceso civil eficiente, Universidad de Valencia, Valencia, 2008; Palomo Vélez, D, "Las marcas del proceso oral y escrito diseñado en el Proyecto de nuevo CPC", Revista Chilena de Derecho, 2009. 
digna", tampoco avanzamos demasiado, puesto que la forma en que se recoge el debido proceso es bastante exigua ${ }^{19}$.

En el proceso laboral oral, se establece como principio el impulso procesal de oficio (art. 425 del Código del Trabajo) y a lo largo de las normas procedimentales, se contemplan además una serie de normas que habilitan al juez a disponer de oficio lo que le parezca pertinente, sin más restricciones que los recursos que tienen las partes en las audiencias o fuera de ellas, facilitando lo que hemos Ilamado la adquisición del proceso por parte del juez, toda vez que sus poderes públicos explícitos son tan exorbitantes, que pueden llegar incluso al punto (impresentable) de sustituir a las partes. Existen algunos jueces, pocos afortunadamente, que estiman que son ellos los primeros que interrogan y luego si las partes estiman que falta algo por inquirir pueden hacerlo, con la agravante que ellos mismos consideran que sus preguntas no son objetables, provocando que la información que se ingresa al proceso no puede ser fiable.

No se contemplan en el proceso laboral oral reales restricciones a lo que se ha Ilamado el monopolio de la violencia simbólica legítima, que implica fundamentalmente que es el Estado el que detenta objetivamente el poder en el proceso. Este poder, que ha sido un elemento integrante de la formación del Estado, apareja la imposibilidad que cualquiera pueda tomar justicia por mano propia, pero también implica que el Estado debe otorgar una tutela judicial efectiva, lo que se da a través de un proceso racional y justo, que debe contener herramientas razonables de control por las partes a la actuación del juez, más aún cuando éste tiene reforzados poderes de oficio, como ocurre en el proceso laboral.

Es justamente lo que no ocurre - en forma expresa - en las normas procesales de nuestro Código. Basta analizar el texto legal (art. 454.6 del Código del Trabajo) para constatar que no existen instrumentos expresos de control de los poderes del juez, y efectivamente éstos consideran que sus preguntas en el interrogatorio testimonial no son susceptibles de control por parte de los litigantes, lo que no sólo es aberrante desde el punto de vista lógico, sino que pone a las partes en situación de desmedro importante si ha ocurrido la adquisición procesal por parte del juez. Si el sentenciador ha adoptado la teoría del caso de una de las partes, o peor aún, tiene una propia y la desarrolla, incluso podríamos tener problemas de congruencia, desde que el Tribunal ha probado

\footnotetext{
${ }^{19}$ De hecho, las discusiones y planteamientos entre Bernales y Evans son bastante poco claras en este aspecto, poniéndose el énfasis en el actuar de la jurisdicción para establecer los parámetros del debido proceso, recogiendo las ideas del due process del sistema anglosajón. Esto, como sabemos, devino en una especie de catálogo de requisitos formales del debido proceso, que no cumplían debidamente con los requerimientos de una real garantía constitucional. Actualmente ha habido un mejor desarrollo de esto, donde podemos ver cómo se ponen los énfasis en estándares de calidad del proceso, más que en requisitos formales, lo que sin duda aporta mucho en la forma y fondo que las distintas legislaciones pueden abordar esta garantía.
} 
cosas distintas que lo que las partes han alegado en el proceso, debiendo las partes tener necesariamente medidas de control.

Por lo anterior estimamos que la sentencia en comento va en la línea correcta desde que considera expresamente que las partes sí tienen medidas de control y sí pueden oponerse a las preguntas del juez. Eso no solamente es de una lógica impecable, sino que también contribuye a generar ambientes procesales seguros, donde todos tienen la convicción de que sus derechos serán resguardados, porque existen herramientas de control suficientes.

La interpretación que hace la sentencia desde el considerando Segundo en adelante en lo que se refiere a la necesariedad que exista control de la calidad de la información que se ingresa al proceso en el juicio oral, resulta de suyo relevante, porque se interpreta desde el debido proceso, superando el déficit de la regulación meramente legal.

Vale decir, frente a la tesis tradicional de los Tribunales de estimar que sus preguntas no son objetables (sólo lo serían las preguntas de las partes), este fallo hace procedente la objeción en contra de este tipo de preguntas. Esto tiene particular importancia de cara a la preparación del recurso de nulidad. En efecto, si el planteamiento de la objeción no alcanza para impedir que se incorpore prueba o información inadmisible al juicio, al menos deberá servir para que se entienda debidamente preparado el recurso de nulidad que se intente luego contra la sentencia. En adelante, por tanto, las objeciones deben ser entendidas como una herramienta para limitar no sólo a aquella parte que no respeta los límites del proceso y coartarlo en esa actuación incorrecta, sino que también posible de utilizar frente a una interrogación judicial que no se ajusta a las exigencias y límites de la Ley.

Lamentablemente esta sentencia, que acierta en su razonamiento, carece de un sustento normativo expreso que así lo señale, porque la interpretación que hace de la norma, si bien aparece como razonable y adecuada, no es literal y eso puede provocar (y de hecho provoca hasta ahora) distintas interpretaciones. Entendemos que es mejor el rol del juez como tercero imparcial que como interviniente y que, para lograrlo, deben contemplarse herramientas o mecanismos que permitan controlar las potestades judiciales oficiosas que la ley laboral ha recogido: instrumentos procesales eficientes, claros y determinados, que entreguen tranquilidad y seguridad a las partes de que se estará frente a un debido proceso, y que la calidad que se ingresa en el proceso es la mejor posible.

\section{UNA INTERPRETACIÓN CORRECTA DE LA FACULTAD JUDICIAL DE INTERROGAR TESTIGOS Y DE LOS DERECHOS DE LAS PARTES EN ESTE MEDIO DE PRUEBA}

Entonces, como hemos venido señalando, nos parece que una interpretación correcta de la potestad de los jueces en el interrogatorio de testigos, debería 
estar marcada por su pasividad en primer lugar, presenciando y escuchando el interrogatorio dirigido por los abogados de las partes, tratando de mantener una posición no interviniente.

No obstante, puesto que nuestra ley ha establecido un juez reforzadamente poderoso, estimamos que debe interpretarse la norma del artículo 454.6 del Código del Trabajo, como una restricción aplicable tanto a las partes como para el Tribunal, tal como lo hace la sentencia (considerandos Quinto y Sexto), porque de esa forma, tendremos la certeza que existe un juicio justo donde todas las partes han tenido la posibilidad de defenderse, exponer su teoría del caso e impedir la adquisición procesal por parte del Tribunal.

En caso contrario, si se permite que el juez actúe sin control alguno, se produce lo que se llama compromiso espiritual del juez y finalmente redunda en una peor justicia, en fallos menos profundos aunque sí más "viscerales", porque en el fondo, el juez interventor al comprometerse, intervenir y apropiarse de todo el proceso, bajo una visión desbordada e incontrolada de la inmediación judicial $^{20}$ afectará, sin duda alguna, su imparcialidad, el debido proceso en general, pero además, provocará sentencias que estarán traspasadas por el compromiso que este juez haya adquirido con su teoría del caso. En cambio, si aceptamos el debido control de la calidad de la información que ingresamos al proceso y fundamentalmente la depuración de ésta a fin de resguardar las teorías del caso de las partes, sin duda que el riesgo señalado se reduciría sustantivamente.

Desde el momento que interpretamos las potestades públicas de oficio del juez en forma extensiva, entonces también tenemos que interpretar los poderes y derechos de las partes de la misma forma, para que el control de la jurisdicción sea razonable, justo, posible y valide finalmente el sistema de enjuiciamiento de manera completa, no exponiéndonos a algo que las más de la veces parece más un simulacro de proceso que uno verdadero.

\section{Corolario. Hacia un ejercicio de la judicatura a través de las partes}

Hemos señalado cómo el ejercicio exorbitante de las potestades públicas del juez en el proceso oral laboral involucra externalidades negativas evidentes para el debido proceso, que pueden salvarse en forma eficiente a través de medidas de control de esta actividad que se dirigen hacia la mejoría sustantiva de la calidad de la información que se ingresa al proceso.

Desde que el juez se compromete con el proceso, disponiendo pruebas, e interviniendo en forma directa y protagónica en su disposición, producción y rendición, se sustituye a la labor de las partes, subsidiando a la parte que

20 Para una visión razonable y controlada de la inmediación judicial, véase especialmente: ANDRés IBÁÑEZ, Perfecto, "Sobre el Valor de la inmediación (una aproximación crítica)", Revista Jueces para la Democracia $\mathrm{N}^{\circ} 46$. 
considera negligente o más débil, o peor aún, pudiendo imponer su especial, particular y personal convicción y punto de vista, sin tener en consideración las teorías del caso de las partes, Ilegando a tener una teoría del caso propia. Por esto, lo que señala el fallo analizado es de vital importancia, porque da cuenta de la importancia de la existencia del control de las partes hacia la actividad del juez oficioso, y además, señala lo relevante que es para la calidad de la información el que precisamente existan estos controles.

Pues bien, las partes deben tener herramientas que les permitan controlar el accionar del juez en el interrogatorio de los testigos, porque de esta manera todos los intervinientes contribuyen para avanzar hacia una jurisdicción objetiva, imparcial, donde el juez pueda tomar decisiones lo más objetivas posibles, desde las teorías del caso de las partes y las pruebas que se rindan, pudiendo ejercer sus poderes públicos explícitos siempre con el debido control de las partes que, desde el derecho al debido proceso y la bilateralidad de la audiencia, gozan de controles indispensables para la calidad de la información que se ingresa en el juicio. Si no se logra eso, esto es, que al menos las partes tengan poderes de control, la posibilidad de que el juez adquiera en el proceso el rol de parte es inmensa y desde luego peligrosa.

Es cierto que con la reforma procesal laboral hemos avanzado una enormidad, opinión que se comparte mayoritariamente especialmente desde el reconocimiento que se hace de la superación de los problemas que estaban asociados a una Justicia que encontraba serias trabas en el soporte formal escrito del modelo anterior que a esa característica (la escrituración de todas las actuaciones), sumaba disgregación y delegación de funciones, con dañinas consecuencias para la seriedad e importancia que cabe asignar a la actividad probatoria, verdadero eje de la estructura de un proceso. El actual modelo, sostenido en la triple exigencia de la inmediación, la concentración y la oralidad ha permitido, que duda cabe, una mayor cercanía del juez con la materia que ha de ser juzgada, siendo una nueva fórmula a través de la que se logra un efectivo acercamiento a la realidad concreta que forma el objeto sustantivo del proceso, concentrándose sus actuaciones principales. En gran medida, gracias al nuevo modelo se redescubre el tribunal y se transforma en el lugar donde se hace el proceso, con la presencia de sus protagonistas esenciales.

Con todo, la recuperación de la figura del juez no puede llevar a la asunción del extremo opuesto a la situación previa a la reforma (el juez sólo al final del trayecto procesal). Es cierto que el modelo permite que el asunto sea mejor seguido por el juez desde su inicio, pero esto no puede autorizar bajo ningún respecto "limpiar" el proceso de un puñado de elementos esenciales que le son connaturales. Debe entenderse que un modelo oral es un modelo más exigente para todos los involucrados, para el juez, pero también para las partes, las que deben tener seguridad de poder realizar las actuaciones que el 
derecho al debido proceso les asegura. Lo bueno es que esa mayor exigencia se compensa con la mayor posibilidad de arribar a sentencias de mayor calidad, sin necesidad de desfigurar la noción de proceso o pasar por encima de los postulados elementales que le dan forma, so pena de comprometer el juez su imparcialidad y el debido respeto a la igualdad de armas. Hemos dicho antes que no nos parece razonable ni conveniente que al tribunal le corresponda sustituir la labor de las partes en la prueba de los hechos, pero ante la nueva regulación - de la que cabe hacerse cargo - corresponde aportar con lo que entendemos una adecuada utilización de los poderes judiciales oficiosos y la necesaria contrapartida que deben tener las partes frente a ellos. Justamente en punto a estos límites es que aún falta mejorar el sistema y así avanzar hacia un proceso dirigido por el juez, pero ejercido por las partes litigantes. Desde el nacimiento y evolución de la oralidad, hasta nuestros días, parece ser que éste es el mejor y más razonable camino. 